\title{
Protocol development in sampling foliicolous lichens in varying leaf areas
}

\section{Paguirigan JAG, Chan AB, Villanueva CKG, Bagaoisan JB and Matalicia SJB}

Department of Biological Sciences, College of Science, University of Santo Tomas, Manila, Philippines

Paguirigan JAG, Bagaoisan JB, Chan AB, Matalicia SJB, Villanueva CKG 2020 - Protocol development in sampling foliicolous lichens in varying leaf areas. Asian Journal of Mycology 3(1), 316-324, Doi 10.5943/ajom/3/1/6

\begin{abstract}
The Philippines, a biodiversity hotspot, harbors various types of flora and fauna and yet its biodiversity is heavily threatened. The country is home to some of the richest and most important ecosystems which house a high percentage of plant and animal life that are vulnerable to extinction. With this, the great interest of research in the country focuses on biodiversity. However, limited information on the Philippine lichen flora is available and foliicolous lichens are still untapped and have long remained unknown. To understand more about these organisms, 140 leaf samples were obtained from 14 host plants collected at Consocep, Mount Isarog, Tigaon, Camarines Sur, Philippines in this study. The mean percentage of foliicolous lichen area compared to the leaf area observed as a whole, by half, and by quarter was analyzed using the analysis of variance (ANOVA). Means and its standard errors (SEM) were used to summarize the percentage of leaf area with foliicolous lichen. The results showed that the foliicolous lichen area measured for the whole, half or quarter leaf areas gave the same data and analysis results, when the leaf age is considered. Linear regression model also showed the positive correlation between the lichen area and the leaf area. A protocol was made for the first time to analyze the distribution of foliicolous lichens on various leaf samples. The developed protocol in studying foliicolous lichens includes (1) the use of mature leaves ( $9^{\text {th }}-13^{\text {th }}$ leaf from the apical bud), (2) use of half or quarter portion of the leaf for longer, wider leaves, (3) use of a $1 \mathrm{~cm} \times 1 \mathrm{~cm}$ transparent leaf grid to measure the leaf area, and (4) the use of regression model to compute the area covered by the foliicolous lichens.
\end{abstract}

Key words - leaves - lichen - linear regression - Mount Isarog - Protocol

\section{Introduction}

The lichen flora of the Philippines as earlier noted by Herre (1946) is one of great interests due to the country's geographical position and tropical climate. The visits of scientists and expatriate experts from America to the country marked the unprecedented progress in the history of Philippine lichenological studies. In the past, rapid and extensive collections were made and complete sets of duplicates were sent to Edward August Vainio in Finland. This has led to the publication of the very first comprehensive treatment of lichens in the Philippines (Gruezo 1979). In 1979, William Gruezo from the University of the Philippines in Los Bańos published the Compendium of Philippine Lichens, where he listed 1,108 taxa (789 species, 3 subspecies, 153 varieties, 28 formae and 1 subformae) distributed in 137 genera. Other lichen studies from various parts of the Philippines include Baguio (Aptroot \& Sipman 1989), Calabarzon (Lucban \& 
Paguirigan 2019), Casaroro Falls and Pulangbato Falls in Valencia, Negros Oriental (Paguirigan et al. 2019), Hundred Islands in Pangasinan (Bawingan et al. 2014), Kalahan Forest Reserve in Nueva Vizcaya (Tabaquero et al. 2013), Palawan (Sipman et al. 2013), and Mainit Hot Spring in Compostela Valley (Domingo et al. 2015).

The study of Callores (2016) was the first to focus on the Philippine foliicolous lichens. Callores identified 22 species of foliicolous lichens belonging to 13 genera from the two lowland forests in Mindoro Island, Philippines. The identified foliicolous lichens reported in the study include Adercomyces lobolimarginatus, Asterothyrium sp., Byssoloma sp., Calenia sp., Calopadia sp., Coenogonium species (3 species), Echinoplaca species (2 species), Lasioloma sp., Mazosia sp., Porina species (3 species), Sporopodium sp., Strigula species (5 species) and Tricharia species. Among the identified foliicolous lichens, Mazosia rotula showed the highest occurrence followed by Strigula subelegans, thus, they are known as the most common foliicolous lichens. Coenogonium minimum and $C$. iisiidiferum were also identified as new records of Philippine lichens.

Lichens are well-known bio-indicators and have been frequently used to analyze and reveal the condition of the environment (Ardelean et al. 2015). Foliicolous lichens are found growing on leaves and develop only as very thin, crust-like structures found on the upper surface of leaves (Favero-Longo \& Piervittori 2010). They are mostly present in undisturbed rain forests at low elevations, though they can be found in tropical and subtropical forests (Serusiaux 1989). Studies on foliicolous lichens are very limited. There is a pronounced lack of information specifically on other aspects of the life of these interesting organisms (Pinokiyo et al. 2006). Furthermore, there is no current method for studying this type of lichens. However, it is known that as leaf age increases the lichen coverage also increases (Rogers et al. 1994).

The study area, Mt. Isarog, is a stratovolcano that rises in the heart of the province of Camarines Sur (Balcita \& Nolasco 2015). It is the highest forested peak in Southern Luzon, which shelters high biodiversity, harboring many endemic and rare species of flora and fauna. Mt. Isarog displays four types of vegetation or natural habitat. From lowland and grassland forest to montane and mossy forest which has an altitude of 1,500 masl. up to the summit (Linis 2014). The natural park has an area of 10,112 ha with an elevation of about 2,000 masl. The mountain spreads out within Naga City and six other municipalities namely Calabanga, Goa, Ocampo, Pili, Tinambac and Tigaon. The study site has a dry period that occurs from January to April. In the lowlands, the temperature ranges from $20.8^{\circ} \mathrm{C}$ in February to $33.6^{\circ} \mathrm{C}$ in May (Balcita \& Nolasco 2015).

This study aimed to develop a protocol for the analysis of the foliicolous lichen distribution in sampling leaf areas to further enhance our current knowledge and understanding of foliicolous lichens. In this study, the significant correlation between leaf area and lichen area was studied through linear regression. Statistical evaluation of the data was performed to describe the relationship between the lichen area and leaf area.

\section{Materials \& Methods}

\section{Study Area}

Mount Isarog National Park $\left(13.6625^{\circ} \mathrm{N}, 123.3711^{\circ} \mathrm{E}\right)$ is located in the province of Camarines Sur, the central part of the Bicol Peninsula about $423 \mathrm{~km}$ south of Manila.

\section{Sampling \& Data Collection}

Mount Isarog displays four major types of vegetation namely lowland forest, grassland, montane forest and mossy forest. From the study area, the sampling sites were selected based on the accessibility, characteristics of the sample site, as well as the presence of suitable host plants. The basis of selecting the host plants in the study includes the abundance of the host plant, ease of collection, and the presence of foliicolous lichens in mature plant host leaves.

The leaves were collected at the foot of Mount Isarog and collection was done through simple random sampling along the trails of Consocep Mountain Resort. Five young and mature leaves 
were collected from each of the fourteen plants. The selection of young leaves starts at the fourth leaf to the eighth leaf from the apical bud. On the other hand, the selection of mature leaves starts at the ninth to thirteenth leaf from the apical bud. All the collected leaves were photographed, placed in polyethene packets, labelled, and later on transferred to a brown paper bag.

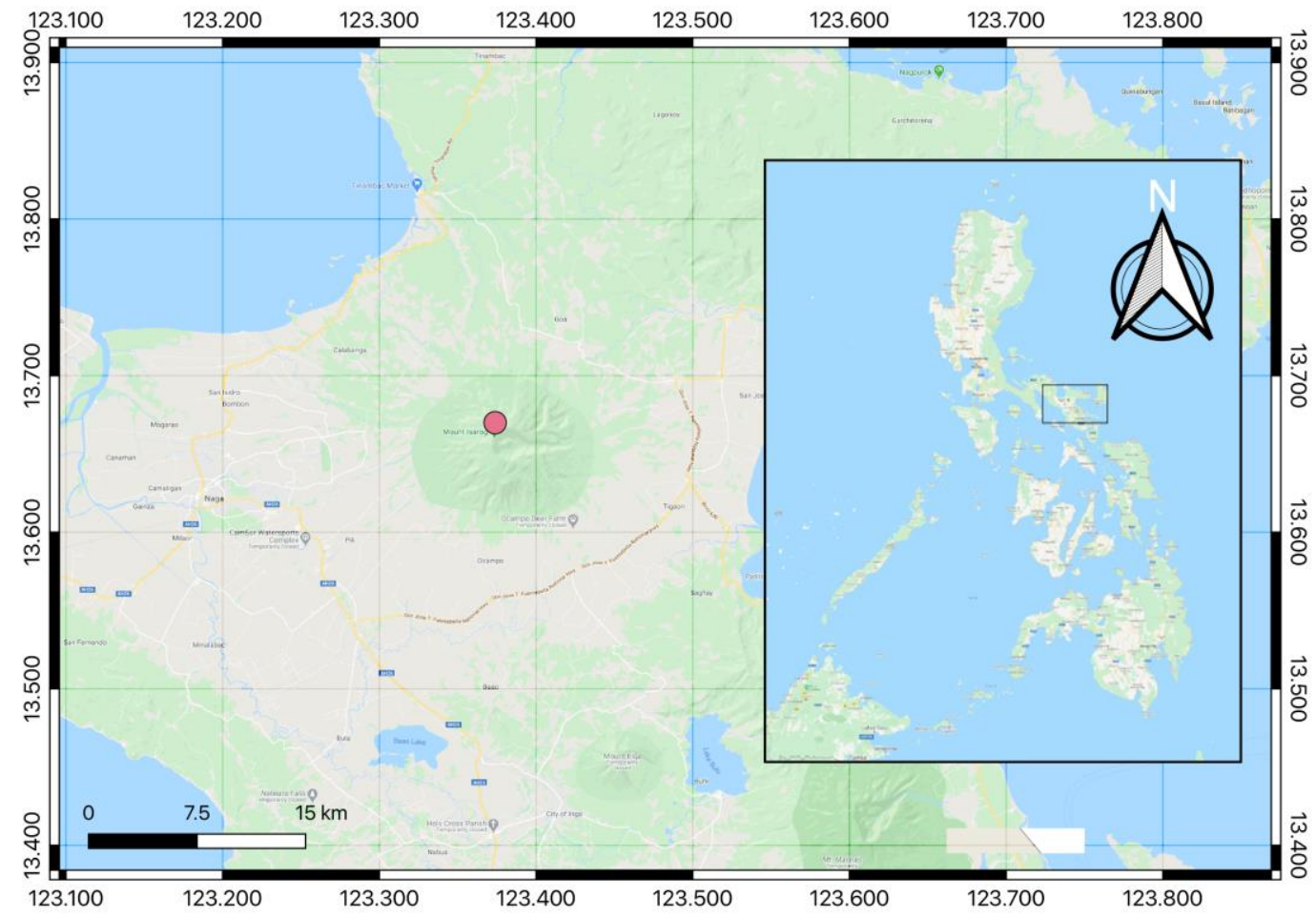

Fig. 1 - Contour Map Mt. Isarog, Camarines Sur.

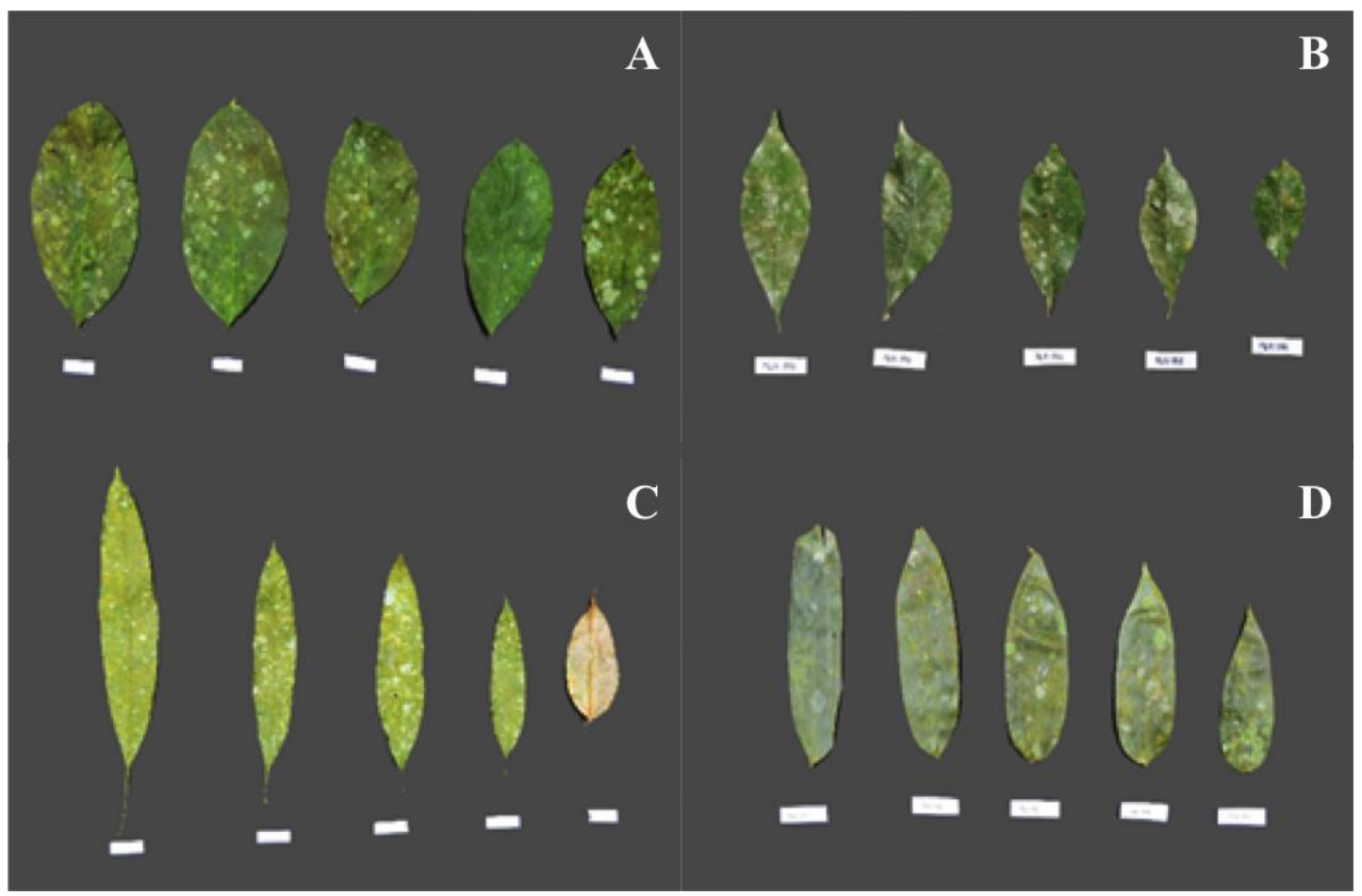

Fig. 2 - Plant host leaves colonized by foliicolous lichens. A Artocarpus heterophyllus. B Cananga odorota. C Mangifera indica. D Bambusoideae. 
To measure the leaf area and lichen area, a transparent grid marked with $1 \mathrm{~cm} \times 1 \mathrm{~cm}$ was placed over the leaf sample (Lücking \& Matzer 2001). Each square occupied by the leaf was counted to get the leaf area and likewise, the squares occupied only by the foliicolous lichens were counted to get the lichen area.

The leaves were then divided into quadrants, starting from the apex to base to get the one-half ratio and then horizontally from the middle of the leaf to get the one-fourth ratio. The percentage of lichen coverage was computed using the formula:

$$
\% \text { Lichen Coverage }=\frac{\text { number of squares occupied by the lichen }}{\text { Total number of squares occupied by the leaf }} \times 100
$$

\section{Statistical Analysis}

Rogers et al. (1994) said that as leaf age increases the lichen coverage also increases. In such a case, there should be a significant difference in the amount of foliicolous lichens present between the young and mature plant host leaves. Aside from that, the use of various portions of the leaf areas for sampling foliicolous lichens with consideration to the leaf age will show no difference.

To analyze and prove the hypothesis, statistical analysis was performed. Means and its standard errors (SEM) were used to summarize the percentage of leaf area with foliicolous lichens. The SEM in the study was used to describe the precision of the sample mean with the true mean of the population. It was also used to determine if the varying leaf portions could be used as an alternative to the long, wide leaves. The mean percentages of leaf area with foliicolous lichens observed in the whole leaf, in a half, and in a quarter of the leaf were compared using the analysis of variance (ANOVA). The $P$ values less than $0.05(P<0.05)$ indicates significant differences.

According to Abdi \& Williams (2010), ANOVA analyzes the differences among group means in a sample. When the ANOVA gives a significant result, this signifies that at least one group differs from the other group, yet this test does not inform on the patterns of differences between the means, thus ANOVA is often followed by post hoc tests. Furthermore, a linear regression model was used to estimate the percentage of leaf area with foliicolous lichens, given the leaf area.

\section{Results}

Of the one hundred and forty leaves that were collected from the host plants, seventy leaves were mature, and seventy leaves were young. However, out of the seventy young leaves, thirty leaves showed no trace of foliicolous lichens.

As seen in Table 1, there were no significant differences $(p>0.05)$ in the percentage of leaf area with foliicolous lichens amongst all plant species. This indicates that the observation method, whether by the whole, by half or by quarter, the observed areas with foliicolous lichens do not differ.

Plants 8, 9, 12 and 13 were the only plants that showed the occurrence of foliicolous lichens in both young \& mature leaves. Thus, to compare the results of these plants of the same species, a different set of analysis was used. The mean percentage of leaf area with foliicolous lichens did not differ and is evident in Plant 8 and Plant 9 which showed $p=0.061$ and $p=0.677$ respectively. In this instance, young leaves could be used as an alternative to the mature plant leaves for studying their foliicolous lichens. However, the mean percentage of leaf area with foliicolous lichens for Plant 12 and Plant 13 is significantly higher on mature than on young leaves $(\mathrm{p}=0.011)$, which means that in the obtained result, it was apparent that matured leaves are more favorable and exhibited a dense aggregation of foliicolous lichens as compared to their young leaves. 
Table 1 Statistical analysis of leaf area covered with foliicolous lichen

\begin{tabular}{lllllc}
\hline & Whole (\%) & Half (\%) & Quarter (\%) & F stat & p-value \\
\hline Overall & $59.26 \pm 2.23$ & $60.73 \pm 1.85$ & $60.34 \pm 1.37$ & 0.201 & 0.818 \\
$\begin{array}{l}\text { Artocarpus } \\
\text { heterophyllus (1) (M) }\end{array}$ & $66.89 \pm 15.22$ & $73.55 \pm 10.43$ & $74.58 \pm 13.16$ & 0.734 & 0.488 \\
Artocarpus & & & & & \\
heterophyllus (2) (M) & $71.48 \pm 6.16$ & $74.09 \pm 12.88$ & $74.38 \pm 16.38$ & 0.065 & 0.937 \\
Bambusoidea (M) & $51.09 \pm 6.58$ & $60.20 \pm 8.22$ & $57.77 \pm 18.05$ & 0.642 & 0.533 \\
Cananga ordorata (M) & $100.00 \pm 0.00$ & $100.00 \pm 0.00$ & $100.00 \pm 0.00$ & 0.000 & 1.000 \\
Hibiscus rosa-sinensis & $72.90 \pm 11.93$ & $73.50 \pm 9.52$ & $74.68 \pm 12.47$ & 0.065 & 0.937 \\
(M) & & & & & \\
Mangifera indica (1) & $65.72 \pm 6.27$ & $72.33 \pm 11.58$ & $73.56 \pm 16.17$ & 0.496 & 0.615 \\
(M) & & & & & \\
Mangifera indica (2) & $68.30 \pm 6.87$ & $71.95 \pm 7.79$ & $71.50 \pm 17.36$ & 0.122 & 0.885 \\
(M) & & & & & \\
Plant (8) (M) & $31.33 \pm 13.64$ & $31.79 \pm 13.06$ & $31.83 \pm 19.60$ & 0.002 & 0.998 \\
Plant (8) (Y) & $23.66 \pm 13.72$ & $23.99 \pm 14.60$ & $25.08 \pm 14.25$ & 0.030 & 0.970 \\
Plant (9) (M) & $54.13 \pm 18.69$ & $57.89 \pm 15.87$ & $57.99 \pm 21.60$ & 0.166 & 0.848 \\
Plant (9) (Y) & $49.85 \pm 16.13$ & $54.59 \pm 21.00$ & $56.39 \pm 24.73$ & 0.048 & 0.953 \\
Plant (10) (M) & $51.45 \pm 28.32$ & $51.46 \pm 29.68$ & $56.62 \pm 26.27$ & 0.142 & 0.868 \\
Plant (11) (M) & $76.44 \pm 16.48$ & $77.10 \pm 10.37$ & $77.93 \pm 15.82$ & 0.026 & 0.975 \\
Plant (12) (M) & $96.79 \pm 6.75$ & $96.14 \pm 6.49$ & $95.40 \pm 6.42$ & 0.109 & 0.897 \\
Plant (12) (Y) & $89.43 \pm 9.66$ & $91.51 \pm 10.19$ & $89.58 \pm 12.04$ & 0.109 & 0.897 \\
Plant (13) (M) & $56.79 \pm 19.39$ & $56.56 \pm 23.77$ & $58.12 \pm 23.36$ & 0.014 & 0.986 \\
Plant (13) (Y) & $37.35 \pm 5.23$ & $36.27 \pm 10.21$ & $37.63 \pm 14.47$ & 0.031 & 0.969 \\
Plant (14) (M) & 49.38 & $42.17 \pm 2.39$ & $37.91 \pm 19.36$ & 0.196 & 0.829 \\
\hline (M) - Mare & & & & \\
\hline
\end{tabular}

$*(\mathrm{M})=$ Mature leaves, $(\mathrm{Y})=$ Young leaves

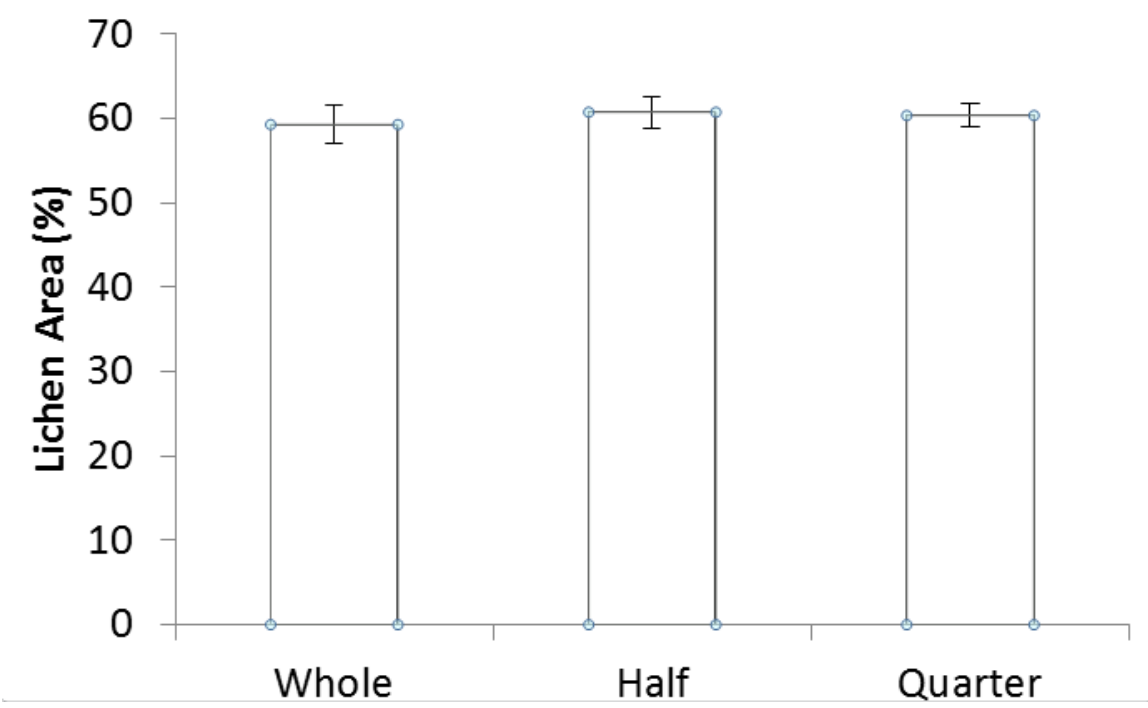

Fig. 3 - Mean percentage and standard error of lichen area in mature leaf samples.

The percentage of lichen area shown in Fig. 3 states that there were no significant differences in the mean percentage of foliicolous lichens when observed as a whole, by half, or by quarter $(p=$ 0.895) of the leaf area. This means that the amount of foliicolous lichens and the sampling leaf area including whole, half and quarter of the leaf area are interrelated and therefore, any one of the three leaf-areas could be used to study foliicolous lichens.

The scatter plot diagram in Figure 4 shows the correlation of the sampling leaf area and the area colonized by the lichens in the young and mature plant leaves. Figure $3 \mathrm{a}$ and $3 \mathrm{c}$ show a weak 
uphill positive linear relationship but the points of Fig. 3a are somewhat scattered in a wider band, whereas Fig. 3b shows a moderate uphill positive linear relationship. For the mature leaves, Fig. 3d has a strong uphill positive relationship and Figs $3 \mathrm{e}$ and $3 \mathrm{f}$ have a very strong uphill positive relationship. The data plotted points of matured leaves positioned very close to each other compared to young leaves. This means that the data in matured leaves are closely associated, therefore, it is more applicable to use for sampling the foliicolous lichens.
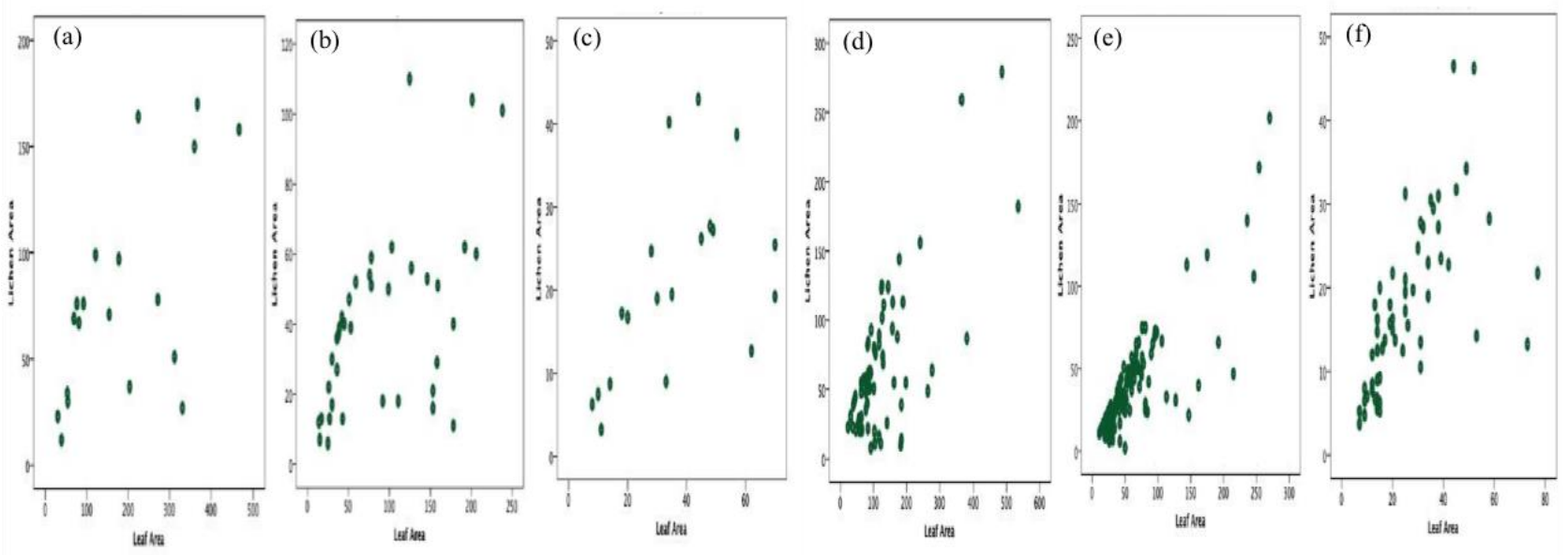

Fig. 4 - Scatterplot of lichen area and leaf area using the young leaves measured as (a) whole. (b) half. (c) quarter and using the matured leaves measured as (d) whole. (e) half. (f) quarter.

Table 2 Regression Models for the Lichen Area based on the Leaf Area

\begin{tabular}{llll}
\hline & & $\mathbf{R}^{\mathbf{2}}$ & \multicolumn{1}{c}{ Equation } \\
\hline \multirow{3}{*}{ Matured } & Whole & 0.502 & Lichen area $=17.896+0.378^{*}$ Leaf Area $+\varepsilon$ \\
& Half & 0.684 & Lichen area $=7.957+0.501^{*}$ Leaf Area $+\varepsilon$ \\
& Quarter & 0.412 & Lichen area $=7.013+0.403^{*}$ Leaf Area $+\varepsilon$ \\
\hline \multirow{3}{*}{ Young } & Whole & 0.392 & Lichen area $=35.246+0.235^{*}$ Leaf Area $+\varepsilon$ \\
& Half & 0.297 & Lichen area $=20.031+0.218^{*}$ Leaf Area $+\varepsilon$ \\
& Quarter & 0.412 & Lichen area $=8.467+0.262^{*}$ Leaf Area $+\varepsilon$ \\
\hline
\end{tabular}

Since there is a linear relationship between the leaf area and the foliicolous lichen area, a linear regression model was done to show that the percentage of leaf area with foliicolous lichens may be estimated. Using the model, it shows that in mature leaves, as the leaf area increases by one unit, the leaf area with foliicolous lichens increases by 0.378 units [95\% CI: 0.287 to 0.468 ], 0.501 units [95\% CI: 0.439 to 0.562 ] and 0.403 units [95\% CI: 0.275 to 0.531 ] for the whole, half and quarter of the leaf, respectively. For young leaves, when the leaf area increases by one unit, the leaf area with foliicolous lichens increases by 0.235 units [95\% CI: 0.085 to 0.385 ], 0.218 units [95\% CI: 0.104 to 0.314 ] and 0.262 units [95\% CI: 0.189 to 0.335 ] for the whole, half and quarter of the leaf, respectively.

To ensure the validity of the linear regression model, the normal distribution of the residuals is plotted. The histograms in Figure 5 shows that for the mature plants, the residuals for the whole leaf $(p=0.631)$, half leaf $(p=0.071)$ and a quarter of the leaf $(p=0.760)$ showed normal distribution. Likewise, for the young plants, the residuals of the model for the whole leaf $(p=$ $0.761)$, half leaf $(p=0.501)$, and a quarter of the leaf $(p=0.985)$ showed normal distribution (Fig. 5).

In the study, the mature leaves were greatly colonized by foliicolous lichens than the young leaves. This suggests that mature leaves are more applicable to use instead of young leaves for sampling foliicolous lichens. Based on the data from the scatterplot (Fig. 3), the mature leaves 
showed that the plotted points positioned precisely to each other and a strong uphill positive relationship is present in contrast to the young leaves, which showed a weaker uphill positive relationship.
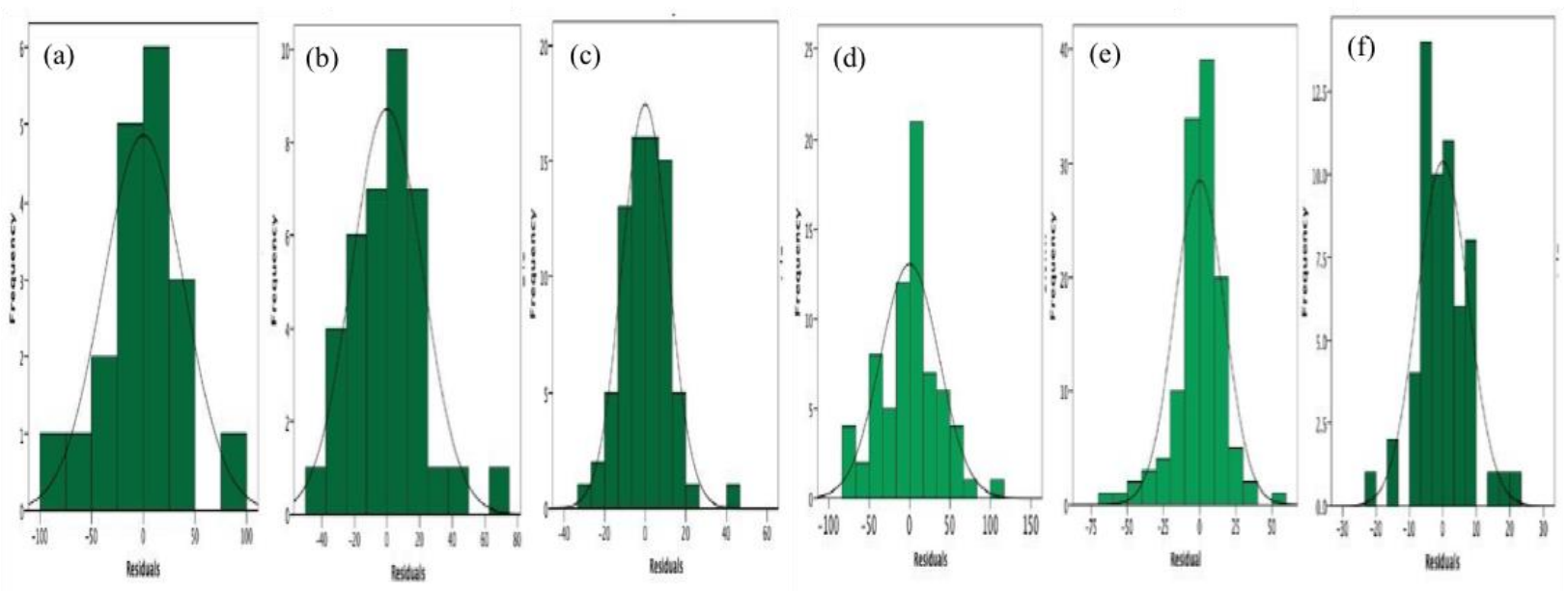

Fig. 5 - Histogram of the linear regression model residuals for young leaves taken as a (a) whole. (b) half. (c) quarter and for mature leaves take as a (d) whole. (e) half. (f) quarter.

\section{Discussions}

This study classified the $4^{\text {th }}$ to $8^{\text {th }}$ leaf from the apical bud as young leaves since previous studies on the colonization of foliicolous lichen species Porina epiphylla, Mazosia phyllosema and Masozia melanophthalma showed an increasing frequency with leaf age from the $5^{\text {th }}$ leaf position (Conran \& Rogers 1983). Another two-lichen species Strigula subtilissima and Strigula complanata appeared later than the other lichen species at the eighth leaf position (Conran \& Rogers 1983) leading to the classification of the $9^{\text {th }}$ to $13^{\text {th }}$ leaf from the apical bud as the mature leaves. Based on the data from the scatterplot, the mature leaves showed that the plotted points positioned precisely to each other and a strong uphill positive relationship is present in contrast to the young leaves, which showed a weaker uphill positive relationship. This means that the data in matured leaves are closely associated and therefore it is more applicable to use for sampling the foliicolous lichens.

Despite the varying rate of foliicolous lichen colonization in the leaves, as seen in Table 1, varying portions of the leaf area show no significant difference for studying the area colonized by foliicolous lichens across all plant species. This indicates that any plant species, the whole leaf, the half or the quarter portion of the leaf can be used to study the area covered with foliicolous lichens with no significant differences. Despite the fact that lichen cover varies greatly from leaf to leaf, and taxon to taxon and could cover $100 \%$ of the leaf surface (Rogers 1995), smaller leaf area such as the half and the quarter portion of the leaf could still be used as an alternative for studying the whole leaf especially for longer and wider leaves.

In this study, several lichen species were found only in mature leaves but not in the young leaves of that specific host plant. This observation was supported by the previous study of Conran \& Rogers (1983), where only a few foliicolous lichen species colonized the young leaves of Wilkiea macrophylla. The study also shows that as the leaf matures, the lichen coverage also increases, which is in congruence with the results presented in Conran \& Rogers (1983). Both studies agree that the rate of foliicolous lichen growth varies from plant to plant though generally, lichen coverage increases with leaf age. Furthermore, the study also adheres to a study conducted by Coley et al. (1993), where rainforest sites in Panama showed a mean lichen cover of 15\% on 1year-old leaves, whereas $25 \%$ on 2 -year-old leaves. In this case, it is believed that several factors affected the lichen colonization in various leaf types of different host plants. Factors affecting the rate of foliicolous lichen growth include the conditions at the time of initial colonization. This 
means that if the environment in which the host plant grows is undergoing a steady change in climate, the conditions at the time when the oldest leaves were initially colonized can be different from those of leaves being currently colonized as observed in the results of the current study. Aside from that, morphological characteristics of the plant leaf including hairs and glands may discourage lichen colonization (Pinokiyo et al. 2006). Another factor that influences lichen colonization and growth is the considerable size of the leaf. Wider leaf size could lead to greater variations in the amount of exposure to desiccated winds than of narrower ones (Monteith \& Unsworth 1990). Wider leaves also tend to have deeper boundary layer across its surface. With these, it should be noted that foliicolous lichens can colonize the entire leaf margin of smaller, narrower host leaves while concentrated in certain areas of the leaf margin in bigger, wider leaves. This study conforms to the idea that there is a difference in the colonization and distribution of the foliicolous lichens in host leaves in terms of leaf size. However, this study proposed that different proportions of the leaf area could be used as a sampling material for the long, narrow leaves that are difficult to deal with when studying foliicolous lichen colonization. This agrees with the study by Rogers (1995), which states that higher frequencies on larger leaves are no surprise for it is reasonable to expect an increased probability of colonization on larger surfaces. However, it should also be noted that the ratio of the leaf area colonized by lichens and the total leaf area are correlated with each other. Because there is a difference in the distribution of the foliicolous lichens on the entire leaf margin, the current study used this idea as the basis for selecting different proportions such as half and a quarter of the leaf area for the experiment. It is then noted that half of the leaf area is obtained by cutting along the midrib of the leaf symmetrically. However, from the half leaf area, the quarter leaf area was obtained by cutting across the margin of the leaf perpendicular to the midrib.

\section{Conclusion}

The result of the study showed that the use of the whole, half or quarter leaf area in sampling foliicolous lichens gives the same data and analysis when leaf age is considered. Mature leaves starting from $9^{\text {th }}$ leaf up to $13^{\text {th }}$ leaf from the apical bud should be used for sampling foliicolous lichens. The relationship between the lichen area and the leaf area displays a positive correlation. The developed protocol can be used as a standard method for sampling foliicolous lichens regardless of the kind of the plant, as it provides the most efficient and convenient way to study this small but remarkable type of lichens.

This study, therefore, suggests that a specific protocol should be utilized for studying the biodiversity of foliicolous lichens, which includes: (1) Collection of mature leaf samples from the 9th to the $13^{\text {th }}$ leaf from the apical bud (the first eight leaves from the apical bud must be excluded), (2) A transparent leaf grid marked with $1 \mathrm{~cm} \times 1 \mathrm{~cm}$ squares should be made and placed over the leaf sample to determine the leaf area and the foliicolous lichen area. The leaf area is the number of squares covered by the leaf sample, (3) For longer, wider leaves, the half or the quarter of the leaf area can be used instead of the whole leaf and (4) The leaf area colonized by foliicolous lichens can be computed using the regression model as long as all the leaf samples are of the same age.

\section{Acknowledgements}

First and foremost, we would like to express our sincere gratitude to the Department of Biological Sciences, University of Santo Tomas who tirelessly gave their support, assistance and immense knowledge all throughout the process. We would like also to thank A. Prof. Xandro Alexi A. Nieto, MS, MEd who imparted his expertise in Statistical Analysis. This paper would have never been accomplished without you and your dedicated involvement.

\section{References}

Abdi H, Williams LJ. 2010 - Tukeys or HSD (Honestly Significant Difference) test. The Sage Dictionary of Statistics. 
Aptroot A, Sipman H. 1989 - New lichen records from the Philippines. Acta Bryolichenologica Asiatica 1: 31-41.

Ardelean IV, Keller C, Scheidegger C. 2015 - Effects of Management on Lichen Species Richness Ecological Traits and Community Structure in the Rodnei Mountains National Park (Romania). PLoSONE.

Balcita J, Nolasco C. 2015 - Mt. Isarog Natural Park. Downloaded on June 25, 2018 from http://www.iapad.org/wp-content/uploads/2015/09/profile_mt_isarog.pdf

Bawingan PA, Pinas A, Amoncio R, Amilao D. et al. 2014 - Diversity and adaptive features of corticolous lichens in the Hundred Islands, Philippines. Philippine Journal of Systematic Biology Vol. VIII.

Callores RFG. 2016 - Comparative diversity of foliicolous lichens in Mt. Siburan and Mt. Malasimbo, Mindoro Island, Philippines. Unpublished Graduate Thesis. University of Santo Tomas

Coley PD, Kursar TA, Machado J. 1993 - Colonization of Tropical Rain Forest Leaves by Epiphylls: Effects of Site and Host Plant Leaf Lifetime. Ecology, 74: 619-623.

Conran J, Rogers R. 1983 - Lichen Succession on Leaves of Wilkiea macrophylla in Southeast Queensland. The Bryologist, 86(4), 347-353.

Domingo WJM, Medina MND, Leano EP. 2015 - Annotated list of Bryophytes and lichen from Mainit Hot Spring Protected landscape, nabunturan, Compostella Valley, Mindanao, Philippines. International Journal of Current research in Biosciences and Plant Biology. 2(10): 110-119.

Favero-Longo SE, Piervittori R. 2010 - Lichen-plant interactions. Journal of Interactions, 5(3), $163-177$.

Gruezo W. 1979 - Compendium of Philippine lichens. Kalikasan, Philippines. Journal Biology 8(3): 267-300.

Herre AWCT. 1946 - The lichen flora of the Philippines. Journal of the Arnold Arboretum 27: 408-412.

Linis VC. 2014 - Biogeographical notes on the moss floras of Bicol Peninsula in Luzon and the Catanduanes Islands, The Philippines. Philippine Journal of Science 142: 119-133

Lucban MC, Paguirigan JAG 2019 - Occurrence of Manglicolous Lichens in Calabarzon, Philippines. Studies in Fungi 4(1), 263-273.

Lücking R, Matzer M. 2001 - High foliicolous lichen alpha-diversity on individual leaves in Costa Rica and Amazonian Ecuador. Biodiversity and Conservation. 12(10), 2139.

Monteith JL, Unsworth MH. 1990 - Principles of environmental physics 2 ed. Edward Arnold, London.

Paguirigan JAG, Bernal KD, Dayto CGA, Ramos MED, Vigo GDS, dela Cruz TEE 2019 - Foliose lichens along the trails of Casaroro Falls and Pulangbato Falls in Valencia, Negros Oriental, Philippines. Studies in Fungi 4(1), 43-49.

Pinokiyo A, Singh KP, Singh JS. 2006 - Leaf colonizing lichens: Their diversity, ecology and future prospects. Curr sci. 90(4):509-518.

Rogers R, Barnes A, Conran J. 1994 - Lichen Succession on Wilkiea Macrophylla Leaves. The Lichenologist, 26(2), 135-147.

Rogers RW. 1995 - Lichen Succession on Leaves of the Rainforest Shrub, Capparis arborea (Capparaceae). Australian Journal of Botany, 43(4), 387.

Serusiaux E. 1989 - Foliicolous lichens: Ecological and chorological data. Botanical Journal of the Linnean Society, 100(1), 87-96.

Sipman HJM, Diederich P, Aptroot A. 2013 - New lichen records and a catalogue of lichens from Palawan island, the Philippines. Philippine Journal of Science 142: 199-210.

Tabaquero A, Bawingan PA, Lücking R. 2013 - Key and Checklist of Graphidaceae lichens in the Kalahan Forest Reserve, Nueva Vizcaya, Philippines. Philippine Journal of Systematic Biology Vol. VII. Retrieved from: Asbp.org.ph 